\title{
Comparison of grape harvesting and sorting methods on factors affecting the must quality
}

\author{
Alessandro Parenti, ${ }^{1}$ Paolo Spugnoli, ${ }^{1}$ Piernicola Masella, ${ }^{1}$ Lorenzo Guerrini, ${ }^{1}$ \\ Stefano Benedettelli, ${ }^{2}$ Stefano Di Blasi ${ }^{3}$ \\ 'Department of Agricultural, Food and Forestry Systems, University of Firenze; \\ ${ }^{2}$ Department of Plant, Soil and Environmental Science, University of Firenze; \\ ${ }^{3}$ Consorzio Tuscania s.r.l., Firenze, Italy
}

\begin{abstract}
This study compared two harvesting techniques (manual and mechanical) and three grape sorting methods (no sorting, manual, and densimetric) in attempts to obtain high-quality must. The trials were carried out in 2009 and 2010 in Tuscany, Italy. The effectiveness of the harvest-sorting chain was assessed on two parameters. Substandard berries (SSB) is the percentage of berries, which do not meet quality standards that enter the winemaking process, and material other than grape (MOG) is a measure of the cleanliness of the berries entering the process. In the two years the trial was run the grape maturation level was widely different; in 2009 the vintage was more far mature than in 2010. With respect to SSB content and harvesting methods, in 2009 (more mature grapes) hand-picking reduced SSB content, while in 2010 there were no differences between the two harvesting methods. In both years, densimetric sorting reduced SSB content, while there were no significant differences between no sorting
\end{abstract}

Correspondence: Lorenzo Guerrini, Department of Agricultural, Food and Forestry Systems, University of Firenze, piazzale delle Cascine 16, 50144 Firenze, Italy.

Tel.: +39.055.2755932.

E-mail: lorenzo.guerrini@unifi.it

Key words: Wine grapes, material other than grapes, sub-standard berries, density sorting, hand sorting, mechanical grape harvest

Acknowledgments: the authors would like to thank the Consorzio Tuscania s.r.l. for its financial support.

Contributions: the authors contributed equally.

Conflict of interest: the authors declare no potential conflict of interest.

Received for publication: 9 February 2015.

Accepted for publication: 21 March 2015.

(C) Copyright A. Parenti et al., 2015

Licensee PAGEPress, Italy

Journal of Agricultural Engineering 2015; XLVI:456

doi:10.4081/jae.2015.456

This article is distributed under the terms of the Creative Commons Attribution Noncommercial License (by-nc 3.0) which permits any noncommercial use, distribution, and reproduction in any medium, provided the original author(s) and source are credited. and manual sorting. In terms of MOG content, both harvesting and sorting results were inconsistent. In 2009, MOG was lower in mechanically harvested grapes; while in 2010 it was lower in hand-picked grapes. As for sorting methods, in 2009 there were no differences in MOG, while in 2010 mechanical sorting produced better results. Our results question whether the post-harvest sorting techniques used by many estates are effective; particularly as the question has received little attention and no previous research has compared methods. Secondly, our study contributes to the debate on the effects of harvesting technique on wine quality.

\section{Introduction}

In modern viticulture there are several practices that aim to obtain high-quality grapes for winemaking in order to meet production targets. The importance of using grapes that are in perfect condition is widely recognised (Allan, 2004; Falconer and Hart, 2005). The two fundamental, key factors related to grape quality are crop purity and ripeness. The former mainly refers to the presence of extraneous materials in the harvested grape; these are commonly designated as materials other than grape (MOG) and include all other vine materials such as leaves, petioles, canes or foreign objects such as stones and parts of trellis. Many authors have noted that the presence of these materials can affect the quality of the wine produced and such materials are generally recognised as detrimental to the harvest (Petrucci and Siegfried, 1976; Clary et al., 1990; Parenti et al., 2005). For example, the Australian Society of Viticulture and Oenology (ASVO) has developed a guide for MOG assessment that establishes the limits for grapes to be accepted by the winery (Allan, 2004). According to this guide, the MOG benchmark level is a content lower than $1 \%$, while content between $1 \%$ and $2 \%$ could be accepted with low risk of quality losses. MOG higher than $3 \%$ is not acceptable for quality wine productions. The second crucial quality aspect for grapes is their ripeness. Among the various descriptors that contribute to the definition of optimal ripeness (e.g. $\mathrm{pH}$, titrable acidity, sugar concentration, phenolic and aromatic maturity), total soluble solids (generally expressed as the Brix degree) are the driving parameter in the choice of harvesting date (Rolle et al., 2012). It is usually assumed that once the target amount of soluble solids (technological maturity) is reached - especially if the harvest does not involve any previous selection or post-harvest sorting - the harvested grapes will only contain a certain amount of sub-standard berries (SSB). SSBs are berries with a level of soluble solids lower than the company's target, and molded or damaged berries. The soluble solid content always varies due to physical and 
environmental factors and, according to Kontoudakis et al. (2011), the heterogeneity in grapes composition could influence the final wine quality. Therefore, it should be considered during harvest and sorting.

Both of the above-mentioned factors can be affected by the harvesting system (i.e. mechanical or manual) and post-harvest sorting that aims to remove MOG and SSB. With respect to harvesting, Petrucci and Siegfred (1976) found high levels of MOG in mechanical harvesting, whereas Falconer et al. (2006) argued that grapes picked by hand should be substantially MOG-free. However, most mechanical harvesting methods cannot detect, and sort SSB. Consequently, higher amount of unripe and damaged berries are found in the harvested grape. Until the 1990's, the conventional harvesting chain in Tuscany, Italy consisted of manual harvesting followed by destemming via mechanical crushing, but no post-harvest sorting. During the 1990's, a regional replanting policy created a large number of new vineyards and mechanical harvesting became more widespread (Intrieri and Filippetti, 2000). However, mechanical harvesting is currently not widely used, probably due to the cost of harvesters and the comparatively small average size (under nine hectares) of estates (Regione Toscana, 2005). In addition, mechanical harvesting has led to concerns about high levels of both SSB and MOG. Since the 1970's harvesters have been equipped with on-board MOG removal devices; nevertheless, Parenti et al. (2005) reported that some materials are not removed (due to their shape, size or friction) and enter into the winemaking process, contributing to the chemical and organoleptic composition of the wine.

In an attempt to overcome these problems, some high quality wine producers, perform a grape selection in the vineyard discarding the sub standard grapes before the mechanical harvesting. Furthermore, in recent years post-harvest sorting has been widely implemented by Tuscan winemakers. The simplest tool to manually remove from grapes the sub-standard berries and the extraneous materials is a vibrating sorting table with conveyor belts that allow a visual inspection of the berries. Another option is automated grape sorting using various specialised machines. Among these devices, densimetric sorting allows the berries separation, after destemming, above and below a preset value. However, they are expensive compared to the sorting table, and in Italy their implementation is still limited to the largest estates that can afford to make the investment.

To the best of our knowledge, there is very little literature dealing with the assessment of MOG and SSB in relation to harvesting and sorting systems. As grape quality may depend on harvest procedures and the effectiveness of sorting methods, our work examines the impact of harvesting and sorting techniques, which are evaluated for the Sangiovese grape in Tuscany, Italy.

\section{Materials and methods}

Trials were carried out during the 2009 and 2010 vintages at the Tenuta le Mortelle (Marchesi Antinori s.r.l.) vineyard in Tuscany, Italy. The experimental vineyard, named Cortigliano, was planted in 2000 in sandy-loam soil with Sangiovese cultivar (clones R23 and R24, rootstock 420A); 6250 vines per hectare were cordon trained in North-South oriented rows.

\section{Experimental design}

A full factorial experimental design was used: two harvesting techniques (manual and mechanical) and three post-harvest sorting methods (manual, mechanical and no sorting) were combined making a total of six treatments. Trials were repeated in twelve replicates (three replicates per day, over four harvest days) for each of the two years.

\section{Harvesting}

In 2009 , trials were carried out $17^{\text {th }}-19^{\text {th }}$ September when grapes reached an average Brix degree ( $\left.{ }^{\circ} \mathrm{Bx}\right)$ of 22.9 . In 2010 they ran from $21^{\text {st }}-23^{\text {rd }}$ September with an average $19.6^{\circ} \mathrm{Bx}$. These average Bx contents were determined with a grape sampling in the vineyard before the harvesting. Grapes were thinned before veraison and selected by hand three days before harvesting with the aim of removing unripe, rotten and mouldy grapes. The target maturation level (determined by the estate's technical staff) was set at $13 \%$ vol. of potential alcohol. While this target was reached in 2009, in 2010 the target maturation level only reached $11.3 \%$ vol. potential alcohol, due to critical grape sanitary and unfavourable climatic conditions. Trials were carried out during the 2009 and 2010 vintages at the Tenuta le Mortelle (Marchesi Antinori s.r.l.) vineyard: i) manual harvesting: hand-picked grapes were collected in a tipping trailer that held about $1200 \mathrm{~kg}$ and quickly transported to the winemaking area; ii) mechanical harvesting: in each trial $2000 \mathrm{~kg}$ of berries were mechanically harvested by self-propelled harvesters, a SAME Deutz-Fahr Agrovitis 200 [2009; SAME Deutz-Fahr Group, Treviglio (BG), Italy] and a Pellenc Active 4560 [2010; Volentieri Pellenc S.r.l., Poggibonsi (SI), Italy]. Both harvesters had horizontal impactors, and are equipped with on-board cleaning devices. Harvesters setting parameters were chosen by the technical staff of the company. Harvesters work at operative speed of about $2 \mathrm{~km} \mathrm{~h}^{-1}$.

Crushing acted as the first step in sorting, as in this phase a device removed part of the MOG. Next, the harvested grapes were separated into three batches for sorting. The separation involved putting the collected berries into boxes, and randomly assigning the boxes to sorting treatments.

\section{Post-harvest sorting methods}

The effectiveness of sorting methods was evaluated by taking $1 \mathrm{~kg}$ of subsamples from batches of about $400 \mathrm{~kg}$ of destemmed grapes, harvested either mechanically or manually: i) no sorting: these grapes were not subject to any post-harvest treatment or sorting technique and were directly sampled from boxes; ii) manual sorting: manual post-harvest sorting of destemmed berries was performed on a sorting table with amoving conveyor belt (IMMA Global A.S., Istanbul, Turkey). The belt speed was set to a constant value of $4.5 \mathrm{~m} \mathrm{~min}^{-1}$. Four workers, two at each side of the conveyor belt, separated green fragments, green or moulded berries and all other extraneous matter; iii) mechanical sorting: mechanical post-harvest sorting was performed using the Triviti Tribaie densimetric system (S6TAV620 model, 2006; Amos Industrie, Beaune, France). This was fed at about $9000 \mathrm{~kg} \mathrm{~h}^{-1}$ (nominal operating capacity is $8000-10,000 \mathrm{~kg} \mathrm{~h}^{-1}$ ) of destemmed grapes via a vibrating trailer. There were two sorting stages. In the first stage, MOG and damaged berries were removed by a rotating disc separator followed by a rotating cylinder.

The second stage involved densimetric separation, following the sorting principle described by Singleton et al. (1966), which is based on the finding that in their own must, berries with density higher than the must sink, while the remaining berries float. In this way berries were split into two fractions: first and second choice.

\section{Harvest and sorting evaluation parameters}

The effectiveness of the different processing methods was assessed in terms of SSB percentage and grams of MOG for kilograms of grapes. For mechanical sorting, only the fraction identified as ripe (i.e. the fraction that sank) was assessed. SSB was defined as the ratio of the weight of damaged (broken and/or moulded) and unripe berries to total berry weight. A soluble solids concentration of $21.5^{\circ} \mathrm{Bx}$ was taken as the reference value and used to determinate SSB. About $1 \mathrm{~kg}$ of berries was sampled for each trial and damaged berries were manually 
removed and weighted. Next, the berry content was densimetrically estimated. Berries were immersed in about $40 \mathrm{~L}$ of a sugar/water solution with a preselected density of $1.095 \mathrm{~g} \mathrm{~cm}^{-3}$. Preliminary trials showed that this density threshold separated floating and sinking berries with a soluble sugar concentration lower or higher/equal to the $21.5^{\circ} \mathrm{Bx}$ reference value. This threshold was selected in consultation with the vineyard's technical staff, as it was considered to be the minimum soluble solid concentration for the production of the company's wines. The company's policy was to produce a smaller volume of wine above a fixed minimum quality standard and the threshold was based on the experience of estates producing high-quality Sangiovese wines in Tuscany. However, as Rolle et al. (2012) point out, the choice of the reference level to discriminate between ripe and unripe berries may change and be adapted to different purposes and conditions. Total soluble solids were measured by a digital refractometre (Refracto 30PX; Mettler Toledo GmbH, Schwerzenbach, Switzerland).

MOG content was determined from a sample of approximately $1 \mathrm{~kg}$ of berries in each trial. Berries were inspected for MOG with the aid of five sieves $(400 \times 600 \mathrm{~mm}$ with an average $15 \mathrm{~mm}$ diameter hexagonal mesh) stacked and placed at opposing angles to catch as much MOG as possible. The separated MOG fraction was weighed and expressed as grams per kilogram of the initial sample.

\section{Data analysis}

An analysis of variance (ANOVA) was applied to the data. Harvesting and sorting techniques were considered as fixed effect factors. Where the $\mathrm{F}$ test was significant at the $\mathrm{P}<0.05$ level, Tukey's multiple comparison of means test was applied (ver. 2007; Systat Software Inc., San Jose, CA, USA).

\section{Results and discussion}

In the two years the experiment was run the vintages were subject to pronounced differences in climate. In 2009 temperatures were higher than 2010 (the total sum of the daily maximum temperature was $4434^{\circ} \mathrm{C}$ in 2009 compared to $4133^{\circ} \mathrm{C}$ in 2010 ). Huglin's heliothermal index (Huglin, 1978), which estimates the heliothermal potential of a specific climatic condition was 2660 in 2009 , and 2374 in 2010. Total rainfall was similar ( $273 \mathrm{~mm}$ in 2009 compared to $260 \mathrm{~mm}$ in 2010), and the vines did not suffer water stress, as the vineyards were irrigated when the matrical water potential approached the wilting point. The average soluble solid content was $22.9^{\circ} \mathrm{Bx}$ in 2009 , and $19.7^{\circ} \mathrm{Bx}$ in 2010 . This means that in 2010 the majority of berries were considered substandard as they did not meet the oenological target set by the company. The heterogeneity of these two vintages meant that it was not possible to compare samples from the two years against each other; therefore they were assessed separately. More positively, it meant that grape harvesting and sorting parameters could be compared under extremely different conditions.

\section{9 vintage}

The two-way analysis of variance (ANOVA) results for SSB and MOG content are shown in Table 1. A significant difference $(\mathrm{P}=0.05)$ was found for both harvesting and sorting techniques. All berries were fully ripened and a significant difference between SSB content of machineharvested grapes (54.3\%) and hand-picked grapes (33.8\%) was found. During the hand picking, workers visually sorted grapes in the vineyard. Those grapes that did not pass the visual test and did not meet the company's oenological target were left on the vine. In mechanical harvest a similar selection has been performed by the same estate workers a few days before the harvesting. Hence, a grape selection in vineyard has been performed for both harvests: mechanical, and manual. However, this difference in the grapes selection method most likely account for differences between the two harvesting techniques. Whatever the harvesting method, densimetric sorting led to the introduction of fewer sub-standard berries into the winemaking process than other techniques. Surprisingly, no differences were found between manual sorting and no sorting. Therefore in 2009 experimental conditions, manual sorting did not help the company to improve the must quality. MOG introduced into the process by the mechanical harvest $\left(6.0 \mathrm{~g} \mathrm{~kg}^{-1}\right)$ was about half that introduced by hand-picking (10.6 $\mathrm{g} \mathrm{kg}^{-1}$ ). Hence, according to Allen (2004), the mechanical harvested grapes have the benchmark level of MOG content (less than 1\%), and the hand-picked grapes have content between the $1 \%$ and $2 \%$. However, both classes are considered acceptable for quality wine productions. Although there was also a significant interaction between year and sorting technique, there were no significant differences between sorting treatments; in this year, MOG only seemed to be affected by the harvesting technique and not sorting.

\section{0 vintage}

The two-way ANOVA results for SSB and MOG are shown in Table 2. The harvesting methods showed no significant difference in terms of SSB introduced into the winemaking process (about 80\%). In this year, workers attempt to sort the grapes in the vineyard, but they were not able to, because differences in berries appearance (i.e. colour, and mould) were too small to be recognised by the workers. Hence, the mechanically harvested and hand-picked grapes had the same SSB values. In 2010, the harvesting method did not significantly affect SSB

Table 1. Analysis of variance results showing the percentage of sub-standard berries, and the material other than grape content $\left(\mathrm{g} \mathrm{kg}^{-1}\right)$ in the 2009 vintage.

\begin{tabular}{lcc} 
& SSB & MOG \\
Harvest & & \\
Hand-picking & $33.8^{\mathrm{a}}$ & $10.6^{\mathrm{b}}$ \\
Mechanical & $54.4^{\mathrm{b}}$ & $6.0^{\mathrm{a}}$ \\
Sorting & & \\
No sorting & $47.2^{\mathrm{b}}$ & $8.2^{\mathrm{a}}$ \\
Manual & $44.7^{\mathrm{b}}$ & $9.4^{\mathrm{a}}$ \\
Mechanical & $40.3^{\mathrm{a}}$ & $7.2^{\mathrm{a}}$ \\
\hline Harvest $\times$ sorting & $\mathrm{ns}$ & $\mathrm{ns}$ \\
\hline
\end{tabular}

SBB, sub-standard berries; MOG, material other than grape; ns, not significant. ${ }^{\mathrm{a}, \mathrm{b}}$ Different letters indicate statistically significant difference (Tukey's test, $\mathrm{P}<0.05$ ).

Table 2. Analysis of variance results showing the percentage of sub-standard berries, and the material other than grape content $\left(\mathrm{g} \mathrm{kg}^{-1}\right)$ in the 2010 vintage.

\begin{tabular}{lcc} 
& SSB & MOG \\
Harvest & & \\
Hand-picking & $82.7^{\mathrm{a}}$ & $6.0^{\mathrm{a}}$ \\
Mechanical & $80.8^{\mathrm{b}}$ & $11.9^{\mathrm{b}}$ \\
Sorting & & \\
No sorting & $83.7^{\mathrm{b}}$ & $11.3^{\mathrm{a}}$ \\
Manual & $85.0^{\mathrm{b}}$ & $10.2^{\mathrm{a}}$ \\
Mechanical & $76.5^{\mathrm{a}}$ & $5.5^{\mathrm{a}}$ \\
\hline Harvest $\times$ sorting & $\mathrm{ns}$ & $\mathrm{P}=0.05$ \\
\hline
\end{tabular}

SBB, sub-standard berries; MOG, material other than grape; ns, not significant. a,bifferent letters indicate statistically significant difference (Tukey's test, $\mathrm{P}<0.05$ ). 
content. Among the sorting methods, mechanical sorting improved must quality and approximately $8 \%$ less SSB was introduced into the winemaking process than in the other methods. However, here again there were no significant differences between no sorting and manual sorting. The absence of a significant difference between manual sorting and no sorting in both vintages is surprising and, in literature, there is a critical lack of data to confirm or deny these results. One explanation is that on the one hand the human eye cannot recognise differences between very similar berry-ripening levels, and/or on the other hand, workers gradually lose their focus when carrying out this repetitive operation for a long period of time with a consequent reduction in effectiveness.

The mechanical harvest introduced more (about twice as much) MOG into the process than hand-picking. This result contrasted with the 2009 data. However, in both vintages, MOG levels were about the half than those found in previous work (Parenti et al., 2005) for each year/harvest combination. Therefore, in our trials both harvesting methods performed well in terms of MOG content, since wineries typically accept batches with MOG lower than $3 \%$.

Among sorting methods, there was a significant interaction with harvesting techniques. The hand-picked grapes shows no difference in term of MOG among the sorting methods; all MOG values are low, ranging from the $4.6 \mathrm{~g} \mathrm{~kg}^{-1}$ of the densimetric method to the $8.5 \mathrm{~g} \mathrm{~kg}^{-1}$ of the no sorting. In the case of mechanically harvested berries, a significant difference between densimetric and other methods was found; densimetric methods removed about half of the MOG. There were no differences between no sorting and manual sorting.

\section{Conclusions}

This experiment evaluated two harvesting and three sorting methods, utilised in Tuscany for the production of high-quality wines. Our results showed that mechanical harvesting removed the same amount of SSB as hand-picking with less-mature grapes (the case in 2010). In this situation the economic, planning and timing benefits of the technique are obvious and widely-accepted. By contrast, in 2010, mechanical harvesting provides higher value of MOG than hand picking.

In 2009, when grapes were well-ripened, hand-picking performed better in preventing unwanted SSB entering the winemaking process, while performed worse in term of MOG. Hence, which harvesting technique is better depends on the climatic trend and the uniformity of ripening. MOG is particularly affected by the growing season. In fact, during the first year mechanical harvesting introduces in the process about half of materials than hand-picking, while in the second year the opposite occurs. However, the measured MOG values are always in the range of acceptability $(<3 \%)$, and often are under the benchmark value of the $1 \%$. Among sorting systems, the densimetric method was able to separate berries into two classes with noticeably different quality and, under certain conditions, seemed to be more effective in the removal of extraneous material. On the other hand, we found that the widelyused (and thought to be effective) manual sorting method offered no benefit. Sorting tables, currently the most popular choice in Tuscany for high-quality wine production, seem to be ineffective in both preventing the entry of MOG and SSB into the winemaking process.

\section{References}

Allan W. 2004. Winegrape assessment in the vineyard and at the vinery. Winetitles, Adelaide, Australia.

Clary C.D., Steinhauer R.E., Frisinger J.E., Peffer T.E. 1990. Evaluation of machine- vs hand-harvested Chardonnay. Am. J. Enol Vitic. 41:176-86.

Falconer R.J., Hart A. 2005. MOG removal system comes of age. Austr. N. Zeal. Grapegrower Winemaker 501:18-22.

Falconer R.J., Liebich B., Hart A. 2006. Automated color sorting of handharvested Chardonnay. Am. J. Enol. Vitic. 57:491-96.

Huglin P. 1978. Noveau mode d'évaluation des possibilites héliotermiques d'un milieu viticole. pp 89-98 in Proc. Symp. International sur l'ecologie de la Vigne. Ministère de l'Agricolture et de l'Industrie Alimentaire, Costança, Romania.

Intrieri C., Filippetti I. 2000. Innovations and outlook in grapevine training systems and mechanization in North-Central Italy. pp 170184 in Proc. ASEV 50 $0^{\text {th }}$ Annual Meeting, Seattle, WA, USA.

Kontoudakis N., Esteruelas M., Fort F., Canals J.M., De Freitas V., Zamora F. 2011. Influence of the heterogeneity of grape phenolic maturity on wine composition and quality. Food Chem. 124:767-74.

Parenti A., Spugnoli P., Baldi F., Vieri M. 2005. Vendemmia meccanica, M.O.G. e qualità del vino. pp 1-6 In: Proceedings of AIIA, L'ingegneria Agraria per lo Sviluppo Sostenibile dell'Area Mediterranea, Catania, Italy.

Petrucci V.E., Siegfried R. 1976. The extraneous matter in mechanically harvested wine grapes. Am. J. Enol. Vitic. 27:40-1.

Regione Toscana. 2005. Aggiornamento dati censimento agricoltura 2000 - indagine sulla struttura e produzioni delle aziende agricole 2003 - Prime valutazioni sui principali risultati disponibili. Informazioni Statistiche. 9:1-8. Available from: http://ius.regione. toscana.it/cif/infbreve/infbreve0907.pdf

Rolle L., Torchio F., Giacosa S., Segade S.R., Cagnasso E., Gerbi V. 2012. Assessment of physicochemical differences in nebbiolo grape berries from different production areas and sorted by flotation. Am. J. Enol. Vitic. 1-27.

Singleton V.L., Ough C.S., Nelson K.E.I. 1966. Density separations of wine grape berries and ripeness distribution. Am. J. Enol. Vitic. 17:95-105. 